\title{
Clinical Characteristics in Combined Pulmonary Fibrosis and Emphysema Syndrome vs Idiopathic Pulmonary Fibrosis Patients
}

\author{
Jolanda Nikolla MD $^{1}$, Hasan Hafizi ${ }^{2}$ \\ ${ }^{1}$ Pulmonologist, Hygeia Hospital Tirana, Albania \\ 2Professor, Pulmonologist, Head of Pulmonology Department, UH "Shefqet Ndroqi”, Tirana, Albania
}

\begin{abstract}
Aim: To identify differences between combined pulmonary fibrosis and emphysema syndrome (CPFE) and idiopathic pulmonary fibrosis (IPF) by a retrospective comparison of clinical data including clinical characteristics and baseline changes in pulmonary function. Methods: We studied demographic, clinical and physiologic features for two groups of patients, (total N=26) those with CPFE (7 males and 5 females) and them with IPF (5 males and 9 females). Results: The mean age was nearly the same. Predominates males smokers in CPFE.IPF patients had lower FVC and MRC values and higher PO2 values. Conclusions: CPFE syndrome is a distinct entity. These patient are severely ill and should be differentiate from them with IPF.
\end{abstract}

Keywords: Combined Pulmonary Fibrosis and Emphysema, Idiopathic Pulmonary Fibrosis

\section{Introduction}

Combined pulmonary fibrosis and emphysema (CPFE) is characterized by upper lung predominant emphysema and lower lung predominant fibrosis. CPFE is predominant among male smokers and characterized by a relatively preserved lung volume and decreased diffusing capacity .This syndrome has been individualised in 2005 in smokers or ex-smokers [1]. Idiopathic pulmonary fibrosis (IPF) is defined as a specific form of chronic, progressive fibrosing interstitial pneumonia of unknown cause, occurring primarily in older adults, and limited to the lungs. It is characterized by progressive worsening of dyspnea and lung function and is associated with a poor prognosis [2]. Patients with CPFE syndrome present with severe dyspnea and have a worse prognosis than patients with IPF [3].

\section{Methods}

Medical records and HRCT scans from January 2012 through April 2016 were reviewed retrospectively at our hospital. During this period we have had 26 patients with interstitial lung diseases (ILD). Among them, we identified CPFE patients through multidisciplinary discussion between our pulmonologists and radiologists. We diagnosed IPF patients with the HRCT scan imaging patterns according to the new ATS/ERS criteria $[2,4]$.There were 12 patients with CPFE and 14 with IPF. Clinical and demographic data were gathered,such as age, gender, smoking history, dyspnea scale, clubbing, comorbidity, cardiac ultrasound and pulmonary function data. Some clinical characteristics and outcomes of patients with CPFE and IPF were compared.

\section{Statistical Methods}

Clinical data are presented as means \pm SDs or medians (range), depending on distribution. The significance and the relationship between factors were tested using EViews 7 program, a software that processes econometric various statistical difference for testing any hypothesis. Multivariable analysis will express the relationship between several variables with the simple or complex regression and the variance analysis. P-level $<0.05$ was considered as statistically significant.

\section{Results}

The total number of the patients with ILD in the last four years in our hospital was $26(\mathrm{~N}=26) .12(46 \%) \mathrm{CPFE}$ and $14(54 \%)$ IPF. In both groups we found similiarities and features on demographic and pulmonary functional data (Tab 1). In CPFE predominates smokers or ex smokers and all of them are males 7 (66.66\%) .In IPF most of patients are females $9(64.28 \%)$ and predominates patients nonsmokers. Mean age in both diseases is approximately the same $(69.3 \pm$ 7.1 years CPFE/ $68.3 \pm 8.3$ years in IPF). Mean BMI (body mass index) was relatively lower in CPFE than in IPF 27.34 $\pm 9.2 / 29.8 \pm 3.6$ respectively. In smokers and ex smokers patients UPY (Unit Pack Year) values was estimated and we found that patients with CPFE had higher UPY values (Graph 1,2). In both groups the most patients have lived in the urban areas in the major part of their life.

Table 1: Demographic data

\begin{tabular}{|c|c|c|}
\hline & CPFE (n=12) & IPF $(\mathbf{n = 1 4})$ \\
\hline Sex m/f \% & $7(66.66 \%) /$ & $5(35.72 \%) /$ \\
& $5(33.33 \%)$ & $9(64.28 \%)$ \\
\hline Age, years, mean \pm SD & $69.3 \pm 7.1$ & $68.3 \pm 8.3$ \\
\hline BMI kg/m²,mean \pm SD & $27.34 \pm 9.2$ & $29.8 \pm 3.6$ \\
\hline Smoking status, n (\%) & $\mathrm{n}=7$ & $\mathrm{n}=5$ \\
\hline never & $5(41.67 \%)$ & $9(64.28 \%)$ \\
\hline current & $4(33.33 \%)$ & $3(21.43 \%)$ \\
\hline ex-smoker & $3(25 \%)$ & $2(14.29 \%)$ \\
\hline UPY, mean \pm SD & $40.7 \pm 15.6$ & $31 \pm 19.4$ \\
\hline Urban / Rural areas & $6(50 \%) /$ & $10(71.42 \%) /$ \\
& $6(50 \%)$ & $4(28.58 \%)$ \\
\hline
\end{tabular}




\section{International Journal of Science and Research (IJSR) \\ ISSN (Online): 2319-7064}

Index Copernicus Value (2013): 6.14 | Impact Factor (2015): 6.391

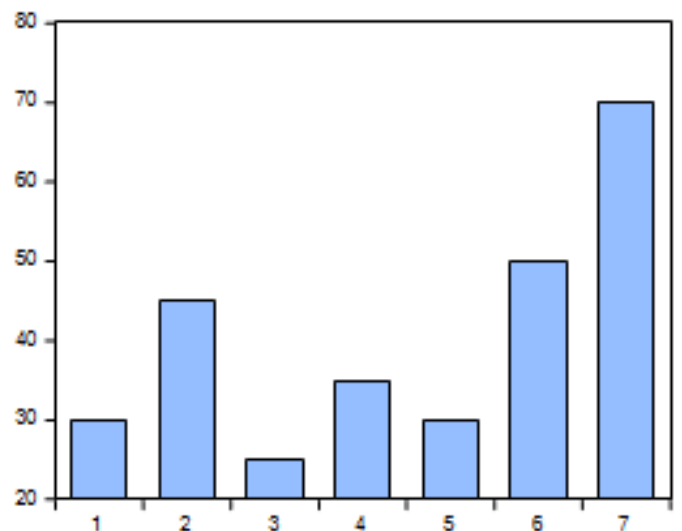

Graph 1: The distribution of UPY in CPFE

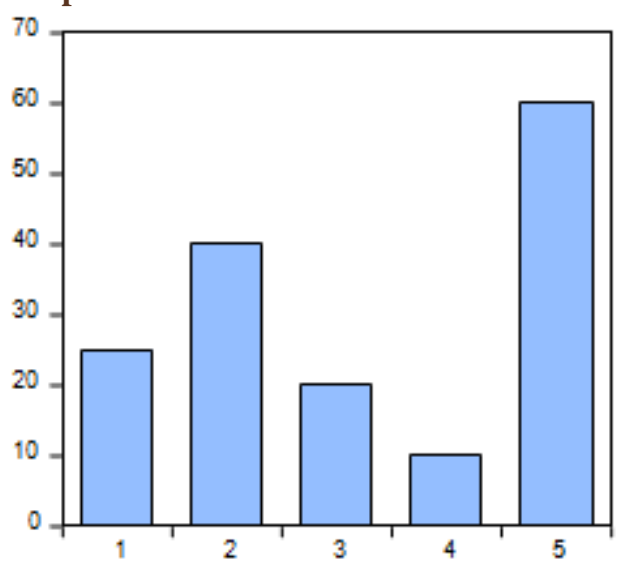

Graph 2: The distribution of UPY in IPF

The mean time from symptoms to diagnosis was $2.08 \pm 0.9$ (years) for CPFE and $1.8 \pm 0.8$. The mean modified Medical Research Council (mMRC) dyspnea score was around 3 for CPFE and 2.8 for IPF. The predicted forced vital capacity (FVC) in percentage was lower in IPF but IT (Tiffneaou Index, the ratio of FEV1/ FVC in percentage), (FEV1, predicted forced expiratory volume in 1 second) was higher in CPFE. The mean partial pressures of oxygen (PaO2) in CPFE patients was $61.5 \pm 9.4 \mathrm{mmHg}$ and in the other group $64.5 \pm 8.3 \mathrm{mmHg}$.

Table 2 : Pulmonary function data

\begin{tabular}{|c|c|c|c|}
\hline & CPFE $(\mathrm{n}=12)$ & $\mathrm{IPF} \quad(\mathrm{n}=14)$ & $\mathrm{P}-$ Value \\
\hline $\mathrm{m}$ MRC, mean $\pm \mathrm{SD}$ & $2.9 \pm 0.5$ & $2.7 \pm 0.5$ & 0.0003 \\
\hline FVC, $\%$ mean \pm SD & $68.5 \pm 11.4$ & $61.7 \pm 13.6$ & 0.004 \\
\hline $\mathrm{IT}, \%$, mean \pm SD & $104.1 \pm 10.3$ & $99 \pm 17.7$ & 0.009 \\
\hline $\mathrm{PO} 2$, mean $\pm \mathrm{SD}$ & $61.5 \pm 9.4 \mathrm{mmHg}$ & $64.5 \pm 8.3$ & 0.0006 \\
\hline Symptoms,mean $\pm \mathrm{SD}$ & $2.08 \pm 0.9$ (years) & $1.8 \pm 0.8$ & 0.7840 \\
\hline
\end{tabular}

Logistic regression analysis was performed for these five variables (tab 2). P - value was calculated and exept for symptoms ( $\mathrm{p}=0.7)$ all the other variables (MRC,FVC,IT,PO2) had $\mathrm{p}<0.05$ that is statistically significant. The pulmonary functional variables make a difference in CPFE and IPF.

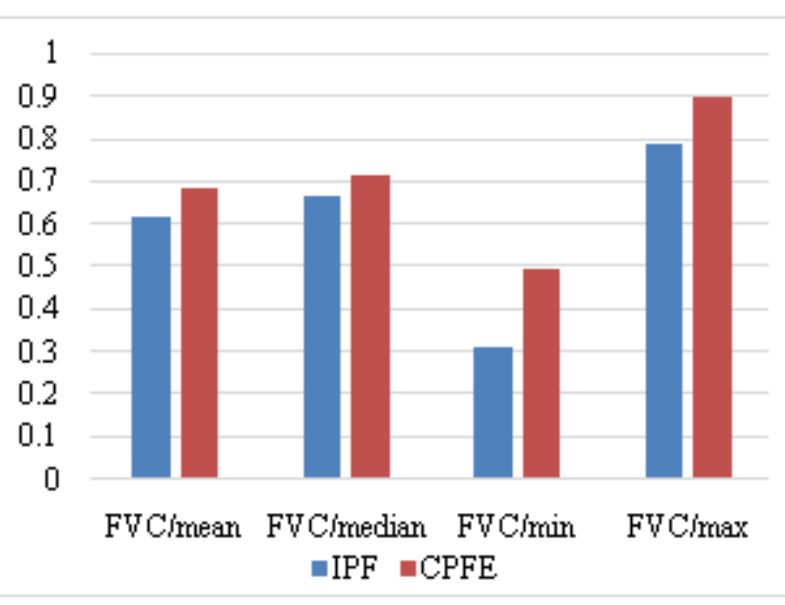

Graph 3: Compared FVC values

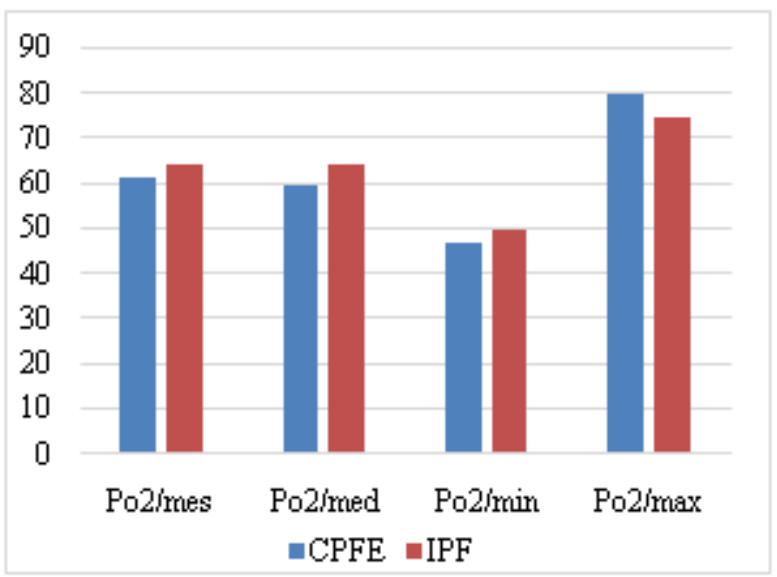

Graph 4: Compared PO2 values

\section{Discussion}

Previous studies have also indicated that smoking is the most important risk factor especially in CPFE [5,6]. In our study predominates males patients in CPFE. In IPF were nonsmokers in most which means that probably the air pollution could possibly participate in the mechanism of IPF [7]. Dyspnea is more severe in CPFE than in IPF. FVC values is lower in IPF patients and PO2 is lower in CPFE [8]. But our study has some limitations : the small number of the patients, it is a retrospective study, in one single center. We focused more on clinical findings but it has to be investigated more on this two entities.

\section{Conclusions}

CPFE is a recently identified syndrome in smokers or exsmokers characterized by dyspnea often severe, preserved lung volumes, severely impaired gas exchanges. Patients with these syndrome are severely ill and they have more needs for oxygen therapy.

\section{References}

[1] Cottin V, Nunes H, Brillet P, Delaval P, Devouassoux G, Tillie-Leblond I, et al. Combined pulmonary fibrosis and emphysema: a distinct underrecognised entity. Eur Respir J 2005; 26(4):586e93. 


\section{International Journal of Science and Research (IJSR) \\ ISSN (Online): 2319-7064}

Index Copernicus Value (2013): 6.14 | Impact Factor (2015): 6.391

[2] Raghu G, Collard HR, Egan JJ, Martinez FJ, Behr J, Brown KK, et al. An officia ATS/ERS/JRS/ALAT statement: idiopathic pulmonary fibrosis: evidencebased guidelines for diagnosis and management. Am J Respir Crit Care Med 2011;183(6):788e824

[3] Fell CD. Idiopathic pulmonary fibrosis: phenotypes and comorbidities. Clin Chest Med 2012; 33:51-57.

[4] American Thoracic Society. American Thoracic Society/European Re- spiratory Society International Multidisciplinary Consensus Classifica- tion of the Idiopathic Interstitial Pneumonias.Am J Respir Crit Care Med 2002; 165: 277-304.

[5] Jankowich MD, Rounds S. Combined pulmonary fibrosis and emphysema alters physiology but has similar mortality to pulmonary fibrosis without emphysema. Lung 2010; 188(5): 365-373.

[6] Balbi B, Cottin V, Singh S, et al. Smoking-related lung diseases: a clinical perspective. Eur Respir J 2010; 35:231-233

[7] Talmadge E King Jr, Annie Pardo, Moisés Selman. Idiopathic pulmonary fibrosis.Lancet 2011; 378: 194961

[8] Hamada K, Nagai S, Tanaka S, et al. Significance of pulmonary arterial pressure and diffusion capacity of the lung as prognos- ticator in patients with idiopathic pulmonary fibrosis. Chest 2007;131: 650-656.

Volume 5 Issue 7, July 2016 www.ijsr.net 